\title{
Economics
}

2020; 9(3): 60-65

http://www.sciencepublishinggroup.com/j/eco

doi: $10.11648 /$ j.eco.20200903.12

ISSN: 2376-659X (Print); ISSN: 2376-6603 (Online)

\section{Criticality Analysis of Shadow Banking System Deregulation}

\author{
Mamadou Mbaye \\ Management of Organization Department, Economic and Social Sciences Research and Training Unit, University of Thies, Thies, Senegal
}

Email address:

m.mbaye@univ-thies.sn

\section{To cite this article:}

Mamadou Mbaye. Criticality Analysis of Shadow Banking System Deregulation. Economics. Vol. 9, No. 3, 2020, pp. 60-65. doi: 10.11648/j.eco.20200903.12

Received: June 28, 2020; Accepted: July 13, 2020; Published: August 10, 2020

\begin{abstract}
The objective of our article is to analyze the criticality of the deregulation of shadow banking system in different economic environments. It is defined like a financial intermediation system carried out outside the framework of classical banking and financial activities. Shadow banking system shows a lot of advantages in terms of the financing of the economy. It is an alternative for the investors and the economic agents. So it constitutes an alternative solution to the problematic of access to financial products of the classical banking system. It offers a possibility of diversification and socialization of risks while allowing an objective and more efficient allocation of financial resources without major constraint. Its activities are not illegal and it completes the classical financial banking system. Its usefulness is well established, but the need for its supervision remains an essential concern for economic agents. If shadow banking system is not regulated, it can bring about, in the market of capitals, toxic financial titles which are created by less credible financial entities. This can cause a disturbance of the economy and a deregulation of the global financial system. Like any other financial system, shadow banking has some risks which it spreads in the economic system if an adequate regulation, with well- established norms, does not govern its implementation.
\end{abstract}

Keywords: Financial System, Shadow Banking, Regulation, Monetary System, Banking System

\section{Introduction}

Most often, shadow banking takes over from traditional finance. The latter, harassed and over-regulated [1], is unable to properly play its original role in supporting the real economy. Indeed, in addition to providing economic agents with an additional platform for monetization, fundraising, and risk transfer, shadow banking facilitates the financialization of the real economy through non-bank, expert and specialized entities, intervening at lower cost in the intermediation chain [2]. The banker who once held a monopoly on expertise which curbs the asymmetry of information between economic agents in financial transactions, is overwhelmed by the speed of innovations due to the multiplicity of economic sectors, the complexity of activities, and the hybridization of financial products. Credit processing now requires a multifaceted and transversal skill that is based on a database, far beyond traditional banking expertise.

Shadow banking assures important functions in the financial system; it offers additional sources of financing and investors alternative solutions; however, it can, in particular, be a source of systemic risk [3]. This vulnerability to the risks which he carries constitutes his Achilles' heel and leads us to believe that it is nothing other than a black hole in the financial system, the privileged receptacle of a multitude of failures. Shadow banking innovates in terms of funding but also in terms of risks, the most obvious of which are the opacity, non-transparency of information, and incomplete traceability of operations. However, it appears itself as a lever for easing prudential standards while being a breathing space that both competes, complements, and sometimes replaces the traditional system. Given its systemic scope, it has certain specificities that make it difficult to supervise. According to reference [4], it is useful for the economy and helps reduce the stringency of regulations.

The principal objective of this article is to analyze the criticality of the deregulation of shadow banking. Our main assumption is that deregulation of shadow banking causes a systemic crisis in the global economy. This assumption is 
supported by current globalization and the decompartmentalization of the international financial system.

\section{Literature Review}

Although shadow banking is a completely new concept, we can, conceptually, go back into economic literature to find the seeds of its appearance. The first postulates come to us from the liberal current of economic thought. It is a question, more precisely of the classic current marked by a radical evolution of mentalities, techniques, and economic processes. This current first appeared in England, theorized by reference [5], reference [6], and reference [7], and then in France with reference [8]. Their work favored the emergence of the Homo Oeconomicus model, which enshrines the individualism of economic agents and the assertion of economic freedom. They denounce state interventionism while advocating socialization through the market, which is the central element of any transaction since it is considered to be the most relevant regulator of economic activity.

Economic freedom is thus exercised on a vast market whose development depends essentially on the removal of administrative obstacles to the free movement of goods, capital, and people, and where the price is freely set, which becomes the fundamental variable ensuring the regulation of the capitalist economy. The price is impersonal, selfregulating, and endogenous compared to the market since it arises within it following the behavior of each economic agent. It is also exogenous because it comes from outside due to the external variables that are imposed on each market player. From half of the 17 th century, with the irresistible rise of monetary creation by banks, we have witnessed a revival of monetary and financial thinking and theories. This is how reference [9] approaches finance from the forces that govern its distribution in space. His work is the first general economic treatise showing the outlines of a new transversal science of wealth. He postulates that the economy (precisely the market) is automatically balanced, that the price level depends on the mechanism of demand and supply and that the interest rate results from the supply but also from the demand for change. He puts the importance of paper money into perspective and considers its beneficial effects to be modest and derisory. We are thus witnessing the beginnings of the dematerialization of means of payment, which is an essential characteristic of shadow banking. Reference [10], still in the wake of the Smithian postulate of the utilitarian reference [11], denounces the implication of the State in a free market, which he considers as an attack on the transactions. It is with reference [12] that we witness the completion of this classic critique of statism. A convinced liberal and partisan, he vigorously defended free trade and competition. With a very minimalistic vision of the state, he confines it to its original, even sovereign, missions of justice and security. He objects to any interference by the public authority in interpersonal economic transactions. He said that "there are too many great men in the world; there are too many legislators, organizers, teachers of societies, leaders of peoples, and fathers of nations, etc. Too many people place themselves above mankind to rule it, too many people make it their business to deal with it. The state is the only great fiction through each individual strives to live at the expense of everyone. "We are thus witnessing the first milestone of free trade which, much later, will generate globalization and the decompartmentalization of financial markets".

The concept of Shadow banking is therefore the result of a free trade system and economic liberalism theorized by reference [5], who said that to be effective, the market must be as large as possible. This free trade covers the free movement of goods, people, and capital. Thus, in the name of this principle, the nations that controlled the markets find themselves without any means of acting on it. By giving up controlling their borders, they have gradually lost control of their economies to the market that dictates the rules of the game. By revisiting the economic thought through the literary works of the precursors of the discipline, we find the theoretical fundamentals of shadow banking and we realize that the path of its emergence has been marked for a very good time. Before the so-called subprime crisis however, there was very little writing on the subject. It will be necessary to wait for the years 2007 and 2008 (those of the crisis) to see the appearance of a river, accusatory literature, which designates shadow banking as the culprit, responsible for the situation.

Obviously, shadow banking is more than a mechanical and rigid accumulation of financial players; it constitutes a system and carries an endogenous and collective counterparty risk that can induce a major systemic crisis. According to reference [2], this gives rise to concern and concern because the activities of its players, which ultimately aim at the transfer, or even the fragmentation and dissemination of credit risk, the transformation of maturity and the leveraging of funds, are structurally and potentially carrying dysfunctions capable of jeopardizing the efficiency of the global financial system.

The financial delinquency, which is specific to it, results from the opacity of hybrid products and the lack of transparency of the transactions that generate them. These activities, although similar to banking activities and highly interconnected with banks, became a source of risk because they have the potential to create multiple forms of feedback in the traditional banking system, which can subsequently impact financial systems and the real economy via this contagion phenomenon [3]. Therefore, he worries at the highest level of decision. Reference [13], in the wake of reference [14], notes the growing concern of the G20 for this sprawling and domineering finance that dodges any form of control.

\section{Criticality of Shadow Banking Deregulation}

We can notice in the shadow banking system discharge that it is still young, capitalizing only twenty years to its 
credit, unlike classic finance, which, barely a decade ago, covered almost all financial transactions and financed the economy. Therefore, before 2008 , its systemic scope and its familiarity with the traditional system had never been the subject of particular attention and specific treatment. Added to addition, according to reference [14], is the fact that shadow banking does not benefit from a public guarantee for its deposits; hence, the absence of prudential regulation. Let us recall that the existence of these guarantees in the classic system was at the origin of the development and the implementation of prudential rules framing the activity of banks.

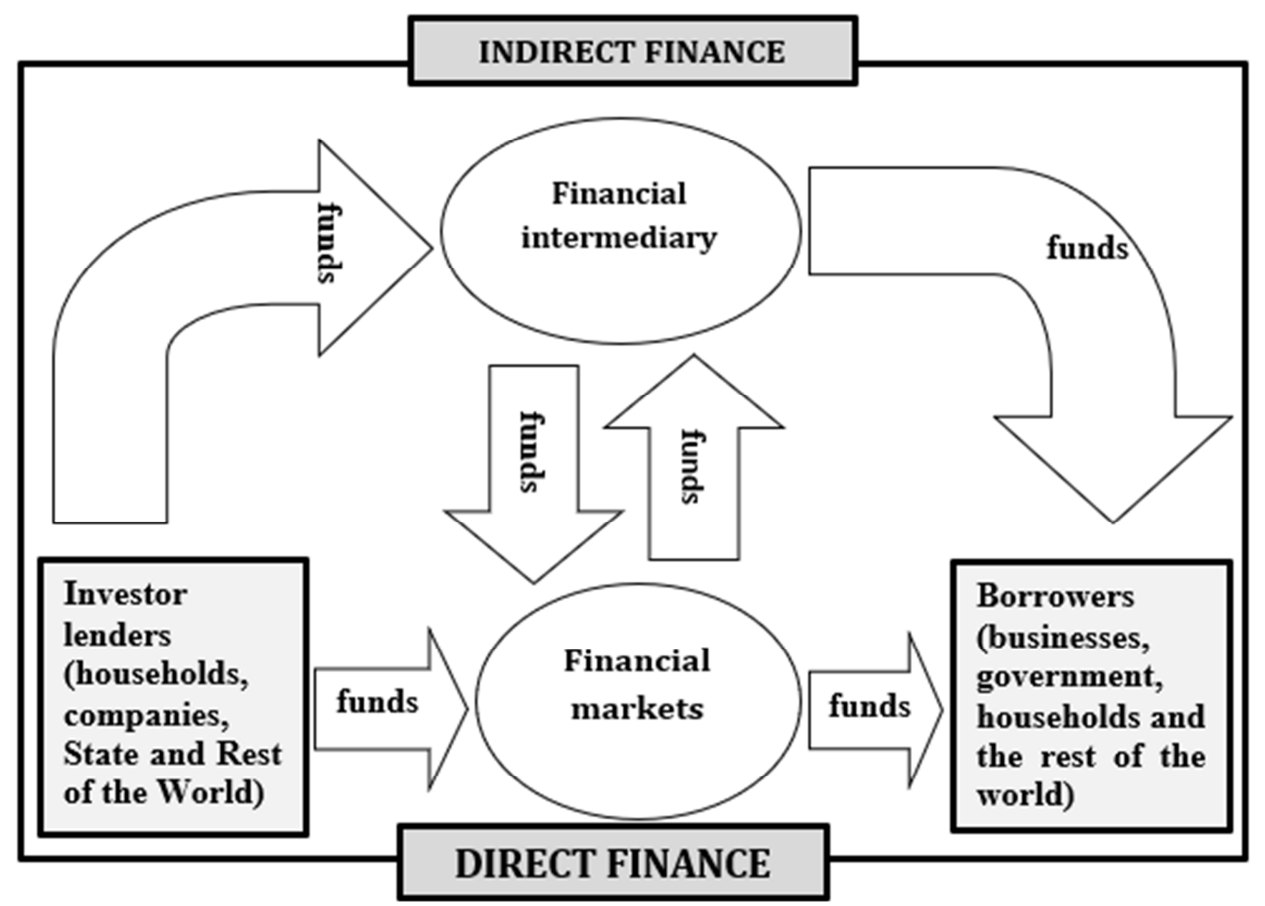

Source: Author (2020)

Figure 1. Flows of funds within the financial system.

For reference [15], the primary objective was to avoid that these guarantees lead to excessive risk-taking and that they do not create a situation of moral hazard. It should be noted that the transformation of deposits into loans intended for agents in need of financing exposes retail banks to financial delinquency, which is specific to them, namely counterparty risk. This prudential regulation also makes it possible to regulate scriptural monetary creation in the fractional system.

The heterogeneous nature of shadow banking largely hinders the application of concerted, harmonized, and everywhere identical rules. Indeed, shadow banking refers to several sometimes very different and often very twisted materialities. It is very fragmented and complex. Also, during this period, the European Parliament has adopted resolution aimed at improving the regulation of shadow banking [16]. Thus, realizing the imperative need for immediate regulation, the European Commission mandates parliamentarians who are striving to codify and standardize the activities of entities in the parallel system, especially those of money system funds and hedge funds. As for the G20, according to reference [17], it insists on the urgent obligation to closely monitor shadow banking, aiming to thwart any attempt to sell risky assets to hedge funds, which are the major players in the parallel system. Such an ambition requires strengthening systemic control processes. With regard to the specific context of developing countries, it must be recognized that transactions carried out on established markets offer more security and stability, unlike those in emerging markets, which, despite being a niche of business, expose agents to the risks inherent in the weakness of the economy, the unfinished financial market (therefore under construction), uncertain economic development, and political instability. In these very unstable markets, default is strongly present and operations are speculative.

The economies of developing countries are poorly diversified and highly vulnerable to inflation. They remain sensitive to fluctuations in floating interest rates and can be deeply disturbed by isolated and even virtually distant events.

Moreover, according to reference [14], investments in the parallel system made in emerging markets are potentially much riskier than those in established markets due to reduced solvency, high public debt, and inappropriate policy debt conversion, market opacity, and unreliable information gaps. The absence of a harmonized rating system and commonly accepted assessment criteria in this economic environment greatly skews the assessment of financial risks. Developing countries have a fragile and precarious monetary system, often at the mercy of large swings in the exchange rate. Several of them permanently or occasionally restrict foreign currency exports. For reference [18], while hedging can, to some extent, reduce the risks of credit or exchange rate inflation, they cannot be totally excluded. Any economic, 
political, and even social disturbance could suddenly and severely destroy the market and lead to a shortage of liquidity, making any withdrawal impossible in the short term. We can also note that in these immature economies, the clearing and settlement systems are often obsolete, poorly harmonized, and may differ from state to state, if at all. This is a source of processing errors and delays in the execution of orders and the delivery of securities [19].

The political risks that result from the inexperience of governments and the versatility of political systems often result in major, systemic, deep, and rapid economic disturbances. They very often involve sequestration without compensation of the assets, the restriction of the rights to dispose of the assets, the fall of values of the assets on instruction or implication of the State for certain sensitive sectors, and the implementation of state reforms often related to monitoring that could negatively impact the transactions initiated. The means of supervision and financial control are insufficiently developed there, implying a deficit characterized by transparency and efficiency of prudential regulation, suddenly accentuating the risk of manipulation of the market by the criminal behavior of the type insider trading [19]. The provisions relating to the protection of lessors are almost non-existent or even very insufficient. With the inexperience of justice helping, the economic agent finds himself unable to enforce his rights in the event of delinquency.

Ultimately, if shadow banking has developed there so spectacularly, in a period of time, it is because it corresponds exactly to a specific need to lighten financial regulations and to efficiently mobilize funds for agents in need of funding. For emerging countries, shadow banking is a relevant response, unfortunately poorly framed, to an efficient demand for liquidity and socialization of risk. The parallel system enriches the competitive environment of the conventional system, completes it, and allows it to develop by providing it with the possibilities of refinancing, transformation of loan maturity, and dilution of risks [20].

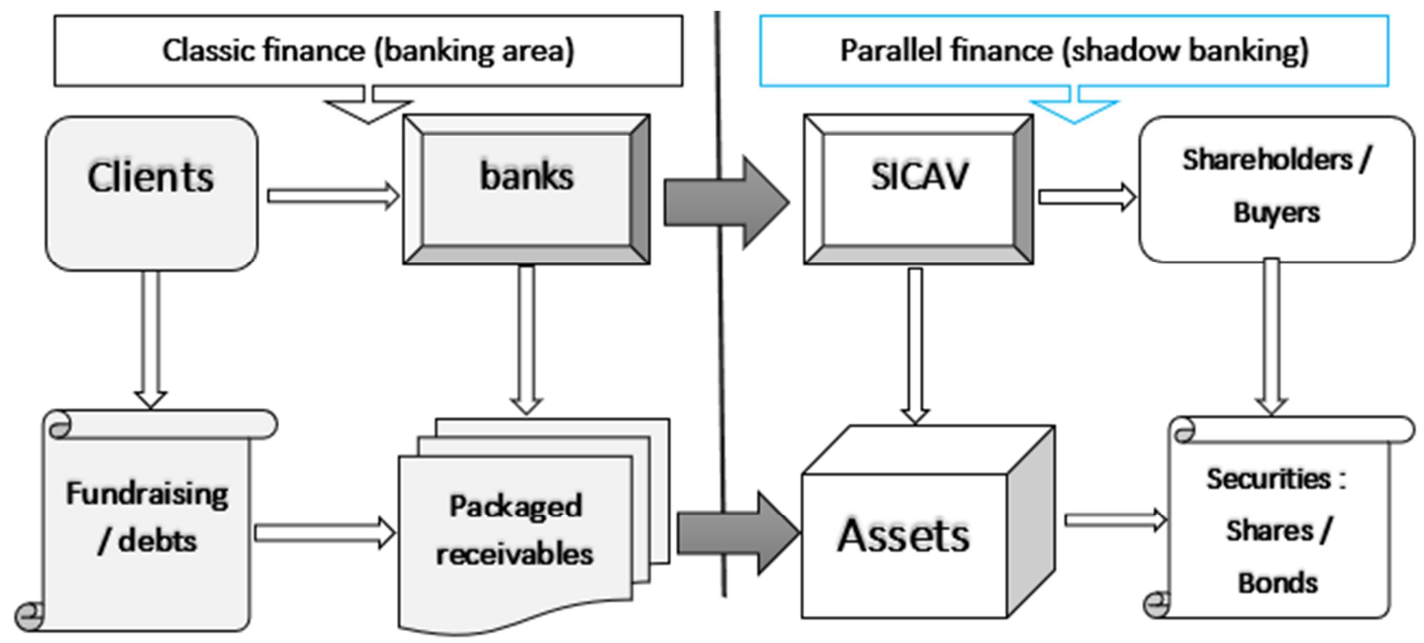

Source: Author (2020)

Figure 2. Complementarity between traditional finance and parallel finance.

The figure above shows us that shadow banking is an inclusive finance that is no longer the exclusive domain of formally established banking and credit establishments. It also involves very unique players, such as households and individuals. According to reference [18], shadow banking does not only have drawbacks. On the contrary, it has a double advantage because it allows the banking system to carry out actions of deconsolidation and, therefore, to optimize its financing capacity, to give investors the possibility of buying a SICAV whose returns in the form Super-dividends are better than those granted by government bonds, the apparent risks of which are assumed to be zero.

The world is a vast place of exchange that goes far beyond physical boundaries. This dematerialization induces a continuous circulation of capital flows in a stateless, multicurrency, and multi-form financial market, characterized by the interdependence of open national economies. Thus, any financial crisis, even geographically distant, takes advantage of this decompartmentalization to transcend porous borders and spread. In reality, according to reference [19], crises are consubstantial with the liveliness of the economy in general and the market in particular. A brief analysis of the history of finance tells us that there were eight in the 17 th century, eighteen in the 19th century, and 33 approximately in the 20 th century reference [19]. At present, with the proliferation of speculative securities in an environment that is not very standardized, the crises of this 21 st century are likely to occupy a high level of systemic crises. It is time to face conscience and determine our responsibility, which is to normalize shadow banking for the stability of emerging economies and the survival of the international economy.

After the mortgage securities crisis (2007/2008), we are in the process of inflating the bubble in the over-the-counter and repo markets at the risk of plunging durably into a socioeconomic crisis from which it will take several years to emerge. In order to untie the bonds of dependence and economic servitude, we need more than ever a solid and diversified financial infrastructure [21]. By socializing risks 
and transforming maturity, shadow banking annihilates aversion and makes it more bearable for a large number of economic players, thus inducing more investment, more production, and more achievements of structural projects likely to boost growth. Direct state intervention as regulators should be the golden rule for ensuring a stable future for the financial system. This interference cannot be long; it should be graduated and targeted. The financial system has disseminated the risks, but there is no question of socializing the consequences and sanctions [22].

\section{Conclusion}

In terms of economic implications, it is a question of restoring to optimal working order a finance strongly abused by questionable transactions, while making a distinction, certainly very difficult to establish with exactitude, between guilty and not guilty reference [19]. Sanctions should be imposed on crooked economic agents who knowingly crossed the "rubicon". The "powder keg" of volatile products should also be cleaned up. Each profession of finance should therefore be analyzed and regulated. Financial intermediation, the poor relation of regulation, should be strongly normalized, and traders should comply with strict rules of ethics and professional conduct. It should be avoided to market a product oozing failure without worrying about the consequences of such a transaction on the real economy. Finance cannot be immoral, and its player must endorse the failures linked to the volatility of their products and to the underlyings, the objects of their transactions [23]. Hedge funds, despite being vectors of risk, are useful and constitute an essential, if not unavoidable link in finance, resolutely turned towards the capital market. It is therefore more relevant to better supervise shadow banking instead of demonizing it. It will be necessary to favor its development in a transparent environment instead of trying to make it disappear or to suffocate it by an overregulation. It will likewise be necessary to advocate the total traceability of transactions, which, without question, is the obligatory passage point of all improvement because it is not relevant for the economic efficiency to favor even implicitly the opacity of a system as vital as is finance [24]. The possibilities for perfecting investment vehicles are as numerous as the strategies deployed by SICAVs and Ad hoc companies to dodge regulation [25] to supervise them. Solutions range from the submission of financial statements to regulatory authorities to the design of a labeled rating attesting to compliance with ethical rules. However, such standardization provisions could not be effective without taking into account the prudential system areas of lawlessness, which constitute the privileged environment for the proliferation of questionable and non-standard financial transactions because almost all investment vehicles are offshore and the cash flows they generate pass through tax havens. Their dismantling is more than ever a requirement for managerial renewal of the financial system. The areas concerned must definitively move away from this so-called banking secrecy and irreversibly move towards more transparency and ethics [23].

Indeed, the current context marked by the hidden funding of terrorist groups requires the indiscriminate management of offshore areas. Better regulation would help curb the recovery of capital flows for criminal purposes. To do this, it will be necessary to:

1. create without delay a supranational supervision of Shadow banking with realistic standards and adapted to the specificities of each economic environment;

2. regulate each finance profession taking into account the specific risks;

3. harmonize the rules so that economic agents who take the same risks are subject to the same prudential regulations;

4. favour a gradual migration from the repo market to a greater structural and normative organization;

5. Develop the reform of the regulatory framework applied to investment vehicles and rating agencies, while promoting rigorous regulation of securitization and supervision of speculative hybrid products.

\section{References}

[1] Betbeze Jean Paul (2015), "Shadow banking versus Banking", Eyrolles Group Paris - France.

[2] Blanque Pascal (2015), "Market finance, changes in financing for the economy and risk", Eyrolles Group.

[3] Baudu François and Constantin MELLIOS, (2015) "Shadow banking, an alternative in financing the economy?" Eyrolles Edition.

[4] Chambon Jean Louis (2015), "Shadow banking, what is parallel finance", Eyrolles Edition Paris - France.

[5] Adam Smith (1776), "the nature and causes of the wealth", Garner collection and Flammarion edition.

[6] Thomas MALTHUS (1798), "Essay on the Principle of the Population", Edition Flammarion Paris, Flammarion, France.

[7] David Ricardo (1817), "Principles of Political Economy and Taxation”, Garnier collection Flammarion Edition Paris, 1992.

[8] Say Jean Baptiste (1803), "Treaty of Political economy", Calmann-Levy Editor Paris.

[9] Cantillon Richard (1755), "Essay on the nature of trade in General", Institute - Coppet Paris 2011- pp 228-235.

[10] Condillac Etienne Bonnot (1775), "commerce and government considered in their mutual relationship", Jombert and Cellot Edition and bookstore street Dauphine France.

[11] Bentham Jérémie (1768), “On judicial organization and codification”, Belgian Society of Bookstores pp 466-495.

[12] Bastiat F (1850), "The Law", Mugron Edition Charbon Collection Paris -pp 201-219.

[13] Nouy Daniele (2013), French banking supervisory authority report 2013. 
[14] Plihon D (2010), "The reform of financial regulation", French notebooks ${ }^{\circ}{ }^{359}$, Paris, France.

[15] Mishkin, F. (2017), "The Economics of Money, banking, and financial markets", 10/e edition, new horizons Paris pp 264279.

[16] Pons J. F. and CYRILLE Causse, C. (2013), "Bank and Strategy", Analyze Economica n ${ }^{\circ}$ 301, p. 59 Right, Vol. 16, 5$21, \mathrm{~N} 30$.

[17] Aglietta Michel (2014), "Shadow Banking carries a risk of collective illiquidity", Paris Nanterre University. AGEFI. PARIS.

[18] Pastre Olivier and Jean Marc Sylvestre (2007), "The true novel of the financial crisis". Perrin Edition, 300p, p 45.

[19] Shaxson Nicholas (2012), "Tax havens, investigations into the ravages of neoliberal finance", André Versaille Publisher.
[20] De Boisseu Christian (2015), "shadow banking: opportunity for operators, challenge for regulators", Eyrolles Group France.

[21] Shaw E and KINNON. Mc (1973), "Financial Aspects of Economic Development, American Economic Review, USA Vol. 45, pp. 728-738.

[22] Financial Stability Board (2020), the Global Monitoring Report on Non - Bank Financial Intermediation», annual report on non-bank financial intermediation.

[23] Vernier Eric (2017), "Whitening technical and means of fight”, Dunod Paris France.

[24] Bowman Joel (2018), «Insights into the economy and financial system from teams» Reserve Bank of Australia Bulletin March 2018.

[25] Ottavj Christian (2014), "Currency and financing of the economy”, Hachette Livre. 